\title{
ESTEBAN PINILLA DE LAS HERAS
}

\author{
SISTEMAS ANALITICOS \\ Y SISTEMAS EMPIRICOS \\ EN SOCIOLOGIA POLITICA
}

El tema que me propongo tratar concierne al análisis de los sistemas políticos en términos de relaciones entre los actores. Para ello voy a referirme primeramente a los análisis para los cuales tienen más relevancia las relaciones entre ciertos principios abstractos que entre actores políticos. Doy por supuestos y admitidos ciertos postulados comunes, como por ejemplo que un sistema político es un sistema que produce decisiones de interés social (esto es, que afectan a toda una colectividad o a partes de ella), las cuales son o pueden ser implementadas (consentidas, obedecidas, o impuestas) mediante alguna clase de sanción positiva o negativa.

El texto que sigue a esta introducción puede ser juzgado, con razón, como una archisimplificación; ésta es, o era, sin embargo, necesaria para poder manejar el argumento. Nadie esperará que la diversidad de teorías y variantes de teorías que existen sobre la concepción y funcionamiento de los sistemas políticos, pueda ser resumida en cuatro tipos ideales. Estos los he construido discrecionalmente, pero no arbitrariamente; distinción que me parece fundada por la coherencia interna de los tipos y por la doctrina de los autores a los cuales remiten *.

* La dificultad de construir estos tipos teóricos ideales, resultantes de la simplificación de doctrinas precedentes a las cuales se intenta reducir a los términos mínimamente necesarios y lógicamente organizados, es una dificultad bien conocida de los autores. Basta recordar la perplejidad de Keynes, cuando empezó a escribir su Teoría general y encontró que la doctrina neoclásica, tal como él la concebía, no se encontraba enunciada y organizada en un texto en particular. 
Sistemas analíticos y sistemas empíricos...

CuAtro modelos de sistema polútTico

1. Digamos que disponemos grosso modo de cuatro concepciones mayores del campo analítico cubierto por el concepto «sistema político».

I) Según una concepción clásica, sistema político denota un conjunto de instituciones, normas y actores cuya actividad está reglada por normas de Derecho, para producir decisiones legales.

Según esta concepción, la observancia de las normas de Derecho en el proceso del sistema es condición necesaria de la legalidad del producto, y asimismo de las otras propiedades de éste asociadas a la legalidad (autoridad y legitimidad social). Una parte del producto del sistema consiste, por tanto, en normas que éste elabora para sí mismo, para reglar jurídicamente su propia actividad. Otra parte del producto se dirige a la comunidad política o a partes de ella.

Los elementos componentes de un sistema político según esta concepción clásica, pueden ser resumidos en seis items:

1) Ias instituciones que definen el orden político, esto es, que enuncian una cierta relación, socialmente vigente, entre Derecho y poder; estas instituciones se especifican en normas que son explícitas (aunque no es necesario que estén codificadas unitariamente ni que hayan sido establecidas simultáneamente);

2) las reglas de juego que interpretan a las primeras y que asimismo regulan convencionalmente la interacción de los actores políticos (las cuales suelen ser tácitas);

3) la distribución de funciones entre los actores políticos, la cual es institucional, funcional, y está basada en principios intrínsecos al sistema político (ésto es, no se deriva explícitamente de fuentes sociales exteriores a éste);

4) los actores políticos, designándose por actores tanto cuerpos creados y definidos por las instituciones legales como las asociaciones políticas voluntarias,

5) las decisiones producidas por el sistema, las cuales pueden ser decisiones promulgables con fuerza legal y asimismo acciones ejecutivas y administrativas, 
6) la legitimación social del sistema y de la acción de los actores, la cual es la contrapartida positiva que éstos reciben por su respeto de la legalidad.

Parece ocioso decir que, según esta concepción, las normas legales son susceptibles de ser innovadas y adaptadas, pero que el sistema no puede funcionar si los actores rompen las reglas del juego. Qué se entiende por reglas de juego, podemos mostrarlo por generalización a partir de un ejemplo histórico específico, citando un texto de uno de los clásicos (Dicey):

...customs, practices, maxims, or precepts which are not enforced or recognised by the courts, make up a body not of laws, but of constitutional or political ethics (...) A lawyer cannot master even the legal side of the English constitution without paying some attention to $(. .$.$) those constitutional understandings which necessarily engross$ the attention of historians or of statesmen. (A. V. Dicey, Introduction to the Study of the Law of the Constitution, 1885, cap. XIV, edición 1961, Macmillan, pág. 417).

Si las reglas de juego son rotas por un actor aislado, el sistema tiene recursos contra él, como la exclusión o el ostracismo. Las reglas de juego incluyen la selección de los problemas que se pueden tratar; ésto es, los tabús sobre cuestiones que no se tratarán nunca, porque ningún actor osará plantearlas. Esta dimensión ha sido definida por P. Bachrach y M. S. Baratz como la segunda cara del poder (the second face of power: the power to decide what is an issue and what is a non-issue. Cf., American Pol. Sc. Review, dicbre. 1962, pág. 949). tico es,

II) Según otra concepción funcionalista (sociológica), el sistema poli-

a) un sistema de roles específicos,

b) siendo cada role objeto de una imputación de poder y de responsabilidad,

c) para producir decisiones de interés general,

d) las cuales están orientadas por valores,

e) teniendo como una de sus funciones mayores el control de la acción desviante,

f) manteniéndose el sistema integrado por los valores socialmente compartidos (consensus).

En esta concepción, de un alto nivel de generalidad, el sistema político es una abstracción analítica del sistema más general de relaciones sociales. 
Sistemas analíticos y sistemas empíricos...

Toda relación social en la cual intervienen poder y control, responsabilidad y consensus, puede ser incluida en el sistema político. Sistema político denota en consecuencia no sólo un sistema abstraído sino también un determinado contenido o dimensión de las relaciones sociales; no es necesaria la referencia a una unidad territorial o Estado-nación. La nación y el Estado son fenómenos históricos relativamente recientes, en cambio sistemas políticos los ha habido siempre que unos actores han tomado e impuesto decisiones desde roles específicos.

III) Según otra concepción sociológica, sistema político denota un subsistema de acción social, el cual:

a) transforma recursos sociales no políticos en políticos;

b) los moviliza con fines de poder;

c) produce decisiones de interés general,

d) posee la capacidad de re-equilibrarse en respuesta a los cambios de sus elementos componentes;

e funciona con direccionalidad,

f) posee capacidad de adaptación a condiciones externas a la entidad política.

Reequilibrio, adaptación, direccionalidad, y control, son las propiedades centrales en esta concepción del sistema. Este absorbe demandas, tensiones y apoyos (inputs), los reelabora, selecciona objetivos, produce decisiones (outputs) instrumentalmente necesarias para la operación de otros sistemas o del sistema social más general. El sistema es estable en cuanto está en movimiento, controlado hacia fines específicos. La navegación adecuada depende de una unidad interna del propio sistema (en griego piloto $=$ kubernetes, de donde la imagen cibernética), en la cual actúa una élite política cuya función es optimizar las capacidades antes citadas (reequilibrio en respuesta a los cambios internos, adaptación a los cambios externos). El sistema político es un sistema controlado de producción de decisiones y de transformación de recursos para implementarlas.

IV) Según otra concepción, cuya pertinencia es más bien histórica que sociológica, sistema político es una abstracción analítica de un sistema más general de dominación social. El sistema político es,

a) un sistema de decisión y de coerción,

b) operado por las clases dominantes,

c) el cual mediatiza o resuelve las contradicciones entre estas clases, 
Sistemas analíticos y sistemas empíricos...

d) para realizar sus intereses comunes particulares,

e) produciendo decisiones revestidas de una apariencia de interés general,

f) las cuales reflejan la relación de fuetzas entre clases en el período $y$ en la formación social dados;

g) y son impuestas por un órgano de coerción específico, el Estado.

Más adelante añadiremos nuevas precisiones sobre esta concepción.

2. Ninguna de estas concepciones (ni la adición de ellas) puede llegar a agotar la realidad empírica, en su extensión más general. E inversamente, ninguna realidad empírica particular puede producir la totalidad de relaciones posibles postuladas por cada teoría. Una de las funciones de la teoría consiste precisamente en prever más posibilidades que las del modelo particular.

Antes de pasar del sistema conceptual al mundo empírico, es necesario que completemos el examen comparativo de las cuatro concepciones aquí enunciadas.

Hay un aspecto en el cual la segunda concepción es de naturaleza diferente de las otras tres. Estas suponen implícitamente que un sistema político constituye, en alguna manera no bien definida, pero positivamente observable, una transcripción o traducción, en términos políticos, del estado de relaciones en otro sistema menos abstracto, que sería el de las relaciones de poder entre actores sociales (dinastía y nobleza, nobleza y burguesía, burguesía y clase obrera, etc.). La segunda concepción no remite a un sistema de distribución de poder entre actores sociales, sino a un sistema de valores (culturales).

Dicho ésto, hagamos aparecer otros aspectos de interés, operando mediante la substitución de algunos términos por otros que funcionan como equivalentes.

En la primera concepción, la transcripción de un sistema de relaciones entre actores sociales a un sistema de funciones políticas se manifiesta de dos modos diferentes, segứn que estemos en presencia de:

(a) una sociedad que para abreviar llamaremos integrada, la cual puede ser definida como una comunidad política, y para la cual es pertinente la aplicación del concepto de voluntad general; o bien,

(b) una sociedad escindida en varias dimensiones, sea en subculturas nacionales, sea en modos de producción históricamente no sincrónicos, sea en actores políticos actuantes en procesos de exclusión mutua; sociedad para la cual no será aplicable el concepto de voluntad general sino el de distribución de poder. 
Sistemas analíticos y sistemas empíricos...

En este caso (caso b) el lenguaje constitucional no hace sino transcribir, en las funciones, limitaciones, y eventualmente poderes de veto de los órganos del sistema político, un transitorio equilibrio de fuerzas, correspondiente a un período dado. La complejidad de las instituciones legales puede llegar a ser una materia descifrable sólo por expertos, y tanto más probablemente cuanto más se haya pretendido vincular y limitar, por la vía de la minucia contractual, las capacidades de acción autónoma de los actores. Los poderes (correspondientes a funciones) de los órganos específicamente políticos son entonces una transcripción de los poderes sociales de ciertos actores (ex. gr.: los conflictos constitucionales de la primera mitad del s. XIX en Europa continental, bajo monarquías que no habían aún perdido sus pretrogativas). Dado que este caso posee hoy un interés más bien histórico, en lo sucesivo al hablar de la primera concepción nos remitiremos exclusivamente al caso (a).

En este caso, la teoría supone que la comunidad política hace una delegación de poder. El poder del sistema llamado específicamente político es un poder recibido (delegado) y transformado por él en autoridad. Tal transformación implica pasar de una capacidad social generalizada y difusa a una capacidad organizada, política y específica. Este paso de un sistema a otro es evidente en el uso de expresiones como «voluntad general», de un lado, y «voluntad del Legislador», de otro. Cuál sea la naturaleza substantiva de la voluntad, es una cuestión metafísica que no cabe tratar aquí. Este término, que suena extrañamente a los oídos de los sociólogos y los cientistas políticos, será reconocido como un viejo familiar por los juristas. La voluntad es el fundamento de los actos legalmente trascendentes. La elegancia teórica es fácil de satisfacer si se supone que las decisiones del sistema político son la expresión de la voluntad general.

En la segunda concepción, poder no se diferencia de autoridad. La autoridad es una propiedad intrínseca de toda organización social dotada de roles jerárquicos, por la cual las decisiones de los ocupantes de esos roles son enunciadas y obedecidas como legítimas. La autoridad es una propiedad del sistema de roles; cada role es el lugar de una imputación de autoridad y de responsabilidad (conceptos que están ligados y son función el uno del otro: a mayor autoridad, mayor responsabilidad).

En la tercera concepción, el poder se confunde con la influencia. Influencia denota la probabilidad que posee un actor de alterar el orden de prioridades de otro. La selección de unos objetivos políticos a cumplir y la exclusión de otros, es una consecuencia de un proceso de negociación, o de enfrentamiento, entre actores dotados de distinta influencia. Estos actores son específicamente políticos (élite política, o clase política internamente diferenciadas por la función y/o por los intereses). 
En la cuarta concepción, el poder se confunde con la dominación. Dominación denota una capacidad que poseen ciertos actores, por la cual éstos se apropian permanentemente, y bajo condiciones establecidas por ellos, el producto de la actividad social de otros.

3. En la primera concepción, la transcripción del sistema de relaciones entre actores sociales al sistema de relaciones entre actores políticos, está mediada de un modo muy complejo, que se manifiesta en los cambios mismos de lenguaje: del lenguaje de los intereses de los actores sociales al lenguaje jurídico, y de éste al lenguaje funcional político. Las traducciones desde el primer nivel al último permiten numerosas manipulaciones, hasta que los intereses particulares desaparecen y se habla solamente del interés general.

En la segunda concepción no tiene sentido pensar en una transcripción de un sistema a otro, pues la relación es de inclusión: el sistema político es una dimensión necesaria del sistema social; éste no podría existir sin las funciones de control que realiza el primero.

En la tercera concepción, la transcripción es de un tipo que pudiéramos llamar vectorial: los resultados de la acción del sistema político pueden ser vistos como un vector, cuya direccionalidad depende probabilísticamente de la distribución de influencia entre diversos actores.

En la cuarta concepción la transcripción es directa y determinista: el sistema político es co-variante del sistema de dominación social; siendo mediada la relación entre los dos sistemas únicamente por las organizaciones políticas voluntarias propiamente dichas.

Para la primera concepción, el sistema político tiene una gran autonomía respecto de otros sistemas sociales. Es un sistema autosuficiente.

Para la segunda concepción. no tiene sentido plantearse si el sistema político posee o no autonomía.

Para la tercera concepción, el sistema político posee una autonomía relativa. Esta es débil en cuanto la selección de objetivos y la direccionalidad del sistema dependen de los intereses de los actores más influyentes; es una autonomía más fuerte en cuanto a la capacidad de control del propio sistema (ésto es, sus propiedades de absorber tensiones todo y manteniendo la direccionalidad de su movimiento, y la capacidad de imponer sus decisiones a la entidad política).

Para la cuarta concepción, el sistema político carece de autonomía. Está determinado por las relaciones de fuetzas entre clases.

4. Introduzcamos ahora un término nuevo con el cual hacer aparecer 
Sistemas analíticos y sistemas empíricos...

otros aspectos del análisis. El término sistema de suma cero (o distinta de cero).

Para la primera concepción, no tiene sentido plantearse la cuestión de si el poder que se delega y circula en el interior del sistema político es de suma cero o no. Esto se revela substituyendo voluntad a poder: no tiene sentido la expresión «la distribución de voluntad es de suma cero» (o distinta de cero). Los filósofos del Derecho que dan una definición unitaria y voluntarista del Estado, y la concepción teórica de J. J. Rousseau validan esta proposición. Se está dentro o fuera de la voluntad general; pero ésta es indivisible.

Para la segunda concepción, la distribución de poder (autoridad) evidentemente no es de suma cero. A medida que la organización social se especializa, especifica y diferencia estructural y funcionalmente (como consecuencia del desarrollo de las divisiones social y técnica del trabajo), se crean nuevas organizaciones (empíricas) y nuevos roles jerárquicos, los cuales poseen la propiedad de autoridad. Hay, pues, creación social de autoridad (poder) e incremento del monto global de poder del sistema. Este no es de suma cero.

Para la tercera concepción, el sistema sólo puede ser de suma cero en un caso particular; siendo en los demás de suma no cero. El caso particular es aquél en el cual estén bloqueadas las capacidades de los actores de transformar recursos no políticos en poder político, o poder latente en poder manifiesto. En todos los demás casos, siempre que se halle actuante la capacidad de transformación de recursos (que se manifestará diferencialmente en una nueva estructura de influencias) el sistema será de suma no cero.

Para la cuarta concepción, el sistema es de suma cero. El poder sólo se puede pasar o quitar; un actor sólo puede incrementar su parte de poder recibiéndola o quitándosela a otro. Esto es transparente si se substituye dominación a poder: la relación dominante-dominado y el incremento o disminución de la dominación, sólo pueden ser de suma cero.

5. Introduzcamos ahora un nuevo término, el principio de exclusión.

Para la primera concepción, el principio de exclusión es uno de los principios fundamentales del sistema. El sistema político es el sistema de producción de decisiones legales, y de él están excluidos los actores no dispuestos a someterse a la legalidad explícita y/o a las reglas de juego. Bertrand de Jouvenel lo ha expuesto claramente: «Tout système politique repose en dernière analyse sur la puissance (...) du principe d'exclusion, dont l'expression positive est le ptincipe de légalité» (cf., Rev. Franç., Science Polit., junio 1961, pág. 377). Esta proposición, que es pertinente 
para los actores, lo es asimismo para las decisiones (legales/ilegales: estas últimas serán declaradas jurídicamente «inexistentes», y los actos a los que hubieren dado lugar serán por tanto reversibles).

Para la segunda concepción, no tiene sentido hablar de un principio de exclusión. El sistema político es necesariamente incluyente. La inclusión se manifiesta en dos dimensiones diferentes: la empírica, según la cual la pertenencia a una comunidad política es obligatoria; y la abstracta o conceptual, según la cual toda relación social es en última instancia una relación política.

Para la tercera concepción, el principio de exclusión carece de connotación substantiva. No expresa una relación de Derecho ni una relación de necesidad social. En caso de ser aplicable a esta concepción, lo sería pragmáticamente: si un actor es capaz de transformar recursos no políticos en poder político, se incorporará al sistema de actores sin que los otros actores puedan impedirlo; éstos reconocerán la existencia e influencia del recién llegado al sistema. Pero podrán excluirlo de la unidad de control del sistema, subrayando el caracter elitista de esta última.

Para la cuarta concepción, que haya o no operante un principio de exclusión en el sistema político, no es una cuestión de.Derecho ni de oportunismo, sino una consecuencia del sistema de dominación social. Este último es incluyente por necesidad (la relación de dominación exige la existencia del dominado respecto del dominante). La dominación social puede requerir, según las condiciones históricas y la estructura de clases, la exclusión política. Este sería un caso particular. Generalmente la dominación social setá transcrita en términos políticos, y el sistema político será incluyente de los actores dominados, bajo las condiciones y para los fines decididos por los dominantes.

6. En suma: la segunda concepción es la más general de todas, descansa sobre uno de los postulados «universales» del funcionalismo, el postula-. do de indispensabilidad. Dice que para que un sistema social exista debe haber autoridad. La primera concepción lo admite, pero lo cualifica diciendo que la autoridad debe ser representativa y legal. La tercera concepción dice que es menos importante que la autoridad sea representativa o. legal como que sea eficaz. La cuarta concepción dice que la autoridad es el velo de legitimidad con que se encubre la dominación.

Todas las concepciones (excepto la segunda) admiten diversos tipos de conflicto, pero cada una de ellas visualiza un conflicto fundamental dife-. rente. En la primera concepción, este conflicto ha sido definido clásicamen-. te como la separación entre país legal y país real. Para la segunda concepción (que, teóricamente, no admite conflicto), la historia ha dado una 
Sistemas analíticos y sistemas empíricos.

respuesta: la desacralización de ciertos roles y la imputación de autoridad a nuevos roles, no prevista por el sistema de valores anterior. (En los términos de la propia concepción es posible argumentar que son los valores quienes imputan autoridad a los roles, no los roles quienes distribuyen autoritariamente los valores). En la tercera concepción, el conflicto fundamental se llama entropía positiva: los canales de comunicación entre gobernantes y gobernados están perturbados, los mensajes no circulan y los inputs no se reelaboran. La cuarta concepción es en sí misma una teoría del conflicto, y en este sentido diferente a las demás (su "conflicto» es que no haya conflicto; o en el lenguaje de la praxis política, que haya colaboración de clases en vez de lucha de clases)

\section{Categorías abstractas y CaTegorías analíticas}

1. Pasemos ahora a examinar la pertinencia de estas concepciones para el análisis empírico. Sin necesidad de recurrir a un juego de palabras, digamos que la cuestión de la pertinencia es una cuestión pertinente, salvo en el caso de que se sea un profesional de la sociología política que se contenta sólo con palabras (las cuales reenvían a otras palabras).

Hay ciertamente autores que postulan que, siendo las construcciones conceptuales los objetos científicos por sí mismas, no es condición necesaria, para construir un objeto científico, que los conceptos remitan a observables empíricos. No vamos a entrar aquí en la discusión de este a priori epistemológico, que no compartimos *. Distingamos ahora simplemente dos problemas de naturaleza distinta: la parcialidad y la incompletud.

Las que hasta ahora hemos llamado cuatro concepciones del sistema po-

* Una sencilla observación sobre «cuantificadores» permite ver el primer punto débil de la falacia idealista. Todos los objetos científicos son construcciones conceptuales. Esta proposición, que tiene la forma todos los $A$ son $B$, es verdadera; sin embargo la proposición conversa no es verdadera. La extensión de la clase $B$ no es la misma que la extensión de la clase $A$. Hay construcciones conceptuales que no son objetos científicos. Todos $\operatorname{los} A$ son $B$; algunos $B$ no son $A$. Hasta aquí la función de los cuantificadores (todos, algunos). La cuestión substantiva no puede ser resuelta por vía formal; pero la vía formal es suficiente para demostrar la no identidad de la clase «objeto científico» con la clase «construcción conceptual». 
lítico resumen no sólo teorías organizadas en forma deductiva, sino asimismo modelos (cada modelo siendo una «imagen» en el sentido de Boulding). Sea cual sea el orden de precedencia o de elaboración de teorías y modelos, puede afirmarse que ambos proceden de la percepción, selección, y reelaboración conceptual de ciertas dimensiones o propiedades abstraídas del mundo empírico, y del olvido (o no selección) de otras dimensiones consideradas por un autor como no relevantes. En ciencias sociales, la crítica de la teotía y de los modelos derivados de ella apenas es fundable en que sean parciales (en que retengan sólo algunas propiedades o dimensiones observables para su reelaboración teórica) pues basta mirar en torno nuestro para ver cuán excepcionales son las teorías generales. La pertinencia es un requisito relativo. Una teoría o un modelo pueden ser parciales y pertinentes, si contienen proposiciones susceptibles de ser confirmadas.

Esto nos lleva al problema de la completud. Como sabe cualquier estudiante de lógica, una teoría es incompleta si contiene enunciados que no pueden ser confirmados ni desconfirmados. Simplificando el problema al extremo, diremos que esto es lo que sucede con los conceptos teóricos que tienen significado, pero no remiten a ningún referente empírico (esto es, conceptos cuyo valor heurístico se agota en el campo lingüístico delimitado por la pareja significante/significado, y que no contienen el tercer elemento, no lingüístico). Estas teorías, si han de poseer algún alcance científico, deben pasar por los términos de un modelo, las proposiciones del cuál deben remitir a observables empíricos.

Hay por consiguiente una relación positiva entre el primer problema y el segundo, entre la pertinencia para el análisis y la satisfacción de un requisito lógico.

Introduzcamos un tercer problema, el de la validez social de un modelo. Es un caso posible que algunos especialistas de una ciencia social reconozcan como empíricamente pertinente, o como lógicamente consistente y (eventualmente) completo, un modelo que les propone otro especialista, sin que ello implique que los actores orienten sus conductas por ese modelo, sino por otro que es el socialmente vigente. En este caso tenemos dos explicaciones que se excluyen; por ejemplo, en nuestros cuatro tipos ideales, la primera y la cuarta. Para quienes postulan esta última, la primera concepción es meramente ideológica e incapaz de dar cuenta de la realidad del proceso político; para quienes postulen la primera concepción, la cuarta es parcial y apriorística.

El valor predictivo de un modelo teórico no depende sólo de su pertinencia empírica (la cual en una ciencia social sólo puede ser parcial), de su consistencia lógica y de su completud; depende asimismo de condiciones sociales que están situadas en otro lugar que los requisitos lógicos 
y que los problemas de la adecuación entre enunciados teóricos y observables empíricos.

En una circunstancia histórica como la nuestra, definida por rápidas mutaciones sociales y por el abandono de valores que se consideraban invulnerables a la duda o a la crítica, es preciso disociar la cuestión de la validez teórica de un modelo social de la cuestión de su vigencia social. Las propiedades de pertinencia, consistencia, completud (y por tanto predictibilidad) deben ser examinadas en sí mismas. No es admisible subsumir las dos cuestiones (validez teórica y vigencia social) recurriendo a un relativismo histórico «à la Mannheim». Es cierto que los enunciados científicos son un producto histórico y que ninguna época puede «pensar» por encima de los recursos de que dispone; pero no es menos cierto que hay enunciados que no sobreviven al lugar social y al tiempo en que fueron creados, mientras otros perduran a lo largo de épocas. Son sin duda una minoría, pero son suficientes para llamar la atención sobre propiedades de esos enunciados que los diferencían de sus coetáneos *.

Es necesario tomar en consideración los cuatro problemas: el de la pertinencia, el de la completud, el de la validez teórica, y el de la vigencia social.

Estos problemas están ( $\mathrm{y}$ han sido frecuentemente percibidos como) imbricados. Consecuentemente, se ha pretendido darles una solución global, de las cuales distinguiremos tres: la solución por la negación, la solución idealista clásica, y la solución marxista.

* Lo que significa examinar de nuevo, y a la luz del análisis lógico y del análisis lingüístico, la vieja cuestión de la modernidad de los clásicos. Sería ingenuo declarar resuelta la cosa diciendo que los clásicos se plartearon problemas permanentes de la condición humana o de las relaciones políticas, mientras los otros se plantearon problemas episódicos o permanecieron ciegos en el interior de la caverna. La cuestión es sobre todo pertinente en el dominio de la ciencia política, en cuanto las formas que adoptan las relaciones de poder parecen ser menos invariantes que las formas que adoptan otras relaciones sociales. (Cf., sobre lo actual y lo inactual en la teoría aristotélica de los sistemas políticos, W. J. Mackenzie, Politics and Social Science, Harmondsworth, 1967, passim.) El modelo aristotélico de tres formas «puras» de régimen político y tres formos «degeneradas» que se corresponden a las primeras término a término, la dependencia de cada forma de la estructura de clases y de la actividad social principal de la comunidad política dada, la apertura del modelo para 2dmitir la transformación (no lineal, sino más bien circular) de una forma en otra, a causa de acciones políticas relativamente autónomas, nos presenta un ejemplo de rara perfección teórica. Si las categorías de Aristóteles no son hoy válidas es, entre otras razones, por la extensión con la cual están construidos sus conceptos. Su nivel de generalidad es $\tan$ alto que recubren un número indefinido de observables empíricos. Dándose raramente en la práctica política los tipos puros, ¿qué régimen de los que conocemos no sería hoy definido como oligárquico o como demagógico? 
La primera ha sido ya aludida anteriormente: consiste en esa forma del reduccionismo historicista que evalúa todo enunciado cientifico por el lugar social y el tiempo en que fue producido. Es la negación idealista del problema, pues remite a una especie de ideas platónicas que caracterizarían cada época, o cada cultura, o cada unidad de civilización. Reduce el producto a las condiciones espacio-temporales del proceso, y a éstas las define como una unidad cultural o espiritual.

La segunda «solución» es también idealista, aunque aparentemente, por su caracter positivo, esté en el extremo opuesto a la anterior. Consiste en armar en la cabeza del científico social un conjunto de categorías o conceptos que se constituyen en invariantes históricos (categorías que son eternas), y de las cuales el mundo empírico no presenta más que realizaciones parciales e imperfectas. Como decía Marx, esas categorías eternas estaban dormidas desde el principio de los tiempos en el seno de Dios Padre, esperando que un economista burgués las descubriese (en el diccionario de la lengua de su país). Digamos que hoy el análisis linguístico empieza a permitirnos ver claro en el bosque de la gran teoría general elaborada con sólo los elementos lingüísticos (significantes y significados), sin los elementos no linguísticos (los referentes empíricos); y digamos asimismo que esos científicos sociales ignoran la regla de Durkheim de tomar los hechos sociales como cosas. La gran construcción conceptual, de la cual el mundo empírico es el reflejo impuro, es una construcción meramente semántica; y en cuanto tal es del mayor interés, para examinarla como cosa. El científico social debe distanciarse de su propio lenguaje; debe ver su lenguaje como proceso y como producto (lo cual es hoy posible técnicamente dado el nivel actual de desarrollo de la lógica y de la lingüística); y al distanciarse de su lenguaje, será capaz de establecer, para sí mismo, y para los enunciados de otros científicos sociales, ciertos criterios de validez.

La tercera solución, o solución marxista (habría que decir, propiamente, de Marx, pues no ha recibido la atención que merece en sus soi-disant continuadores), es mucho más compleja de exponer y de analizar. Primeramente, hay que distinguir los casos en que Marx combate la filosofía o la epistemología idealistas (la construcción conceptual con categorías eternas), del caso o casos en los cuales trata de fundar su propio método. Cuando Marx combate las teorías idealistas, se enfrenta a ellas con una argumentación que podríamos definir como su antinomia sociológica (de una gran eficacia polémica pero que es sólo un aspecto de su pensamiento). Esto es visible en la Miseria de la filosofía y en la correspondencia crítica sobre Proudhon. A las categorías ahistóricas que son invariantes conceptuales, abstracciones de las cuales el mundo empírico sería un miserable reflejo, Marx opone el proceso correcto de la abstracción: de las relaciones sociales 
Sistemas analíticos y sistemas empíricos...

reales, a las categorias que las denotan o las reelaboran. Así cada formación social, organizada por un modo de producción, tiene sus relaciones sociales características, las cuales son reelaboradas en categorías conceptuales específicas. Si se examina esta tesis aislada y en sí misma, equivale a una totalización sociológica, la cual sería la otra cara de la medalla del reduccionismo historicista idealista al que aludimos precedentemente. (Algunos autores marxistas creen ser fieles a Marx manteniéndose en este sólo nivel; es el caso de Alain Badiou en Le concept de modèle (París 1969), quien despacha, por así decir, toda la lógica desde Aristóteles al neopositivismo, en unas cuantas líneas, como un producto histórico co-variante de las necesidades empíricas y del estado de desarrollo del cálculo matemático). Sin embargo, Marx no se podía contentar con oponer el materialismo al idealismo; él había leído sus clásicos griegos, y los amaba suficientemente para saber que la acumulación del conocimiento científico no es reducible a las relaciones de producción. Este otro aspecto (el aspecto positivo, no polémico) es visible en $E l$ método en Economía política. Un examen de este texto muestra que Marx asumía la posición científica, ya establecida en su tiempo, según la cual una ciencia debe poseer categorías que son constantes (son los conceptos propios de esa ciencia), y con las cuales se denotan ciertas relaciones (sociales). Estas categorías son llamadas por Marx simples o puras (son universales sans phrase); son por tanto abstracciones que trascienden un lugar social y un tiempo (Marx utiliza un término de Lucrecio, son mors immortalis). Pero cuando se usan estas categorias en el análisis, entonces están socialmente determinadas: denotan unas relaciones sociales específicas. Contrariamente a lo postulado por otros muchos autores en el s. XIx, Marx no participa de una visión progresista del desarrollo conceptual; explícitamente dice que una categoría simple se puede encontrar pura en una sociedad muy compleja, y «desarrollada» en otra sociedad menos compleja. En otro lugar añade que en el análisis del capitalismo, no le interesa el orden histórico de aparición de las categorías, ni tampoco «su sucesiva importancia como factores determinantes del curso de la historia»; lo que le interesa es «su conexión... en la sociedad burguesa».

Marx, que tan positivos esfuerzos realizó para traspasar el velo monetario y el velo ideológico, en sus estudios sobre la economía política prericardiana y ricardiana, nos coloca aquí en el umbral del velo lingüístico, el cual es uno de los problemas fundamentales de la ciencia social (esto es, de las ciencias que no están formalizadas y que no operan con lenguajes completamente codificados). El científico social no posee otro instrumento cognitivo y teórico que el lenguaje común (el instrumento matemático constituyendo hoy un recurso técnico y empírico, no una alternativa al enun- 
ciado teórico). A diferencia de lo que ocurre con el acto de romper el velo ideológico (operación que Marx describió persuasivamente como el reordenamiento de las categorías según su conexión social, que en el caso del capitalismo burgués era la contraria del ordenamiento histórico o «natural»), la operación de romper el velo lingüístico no se resume en la oposición metodológica entre estructura e historia. Marx conduce a un umbral, y nos corresponde hoy aplicar a las ciencias sociales las enseñanzas derivadas de las ciencias positivas, de la lógica formal, y de la crítica semántica.

Uno de los ejemplos ideales a introducir aquí (si no requiriese un largo tratamiento ad boc) versaría sobre el concepto de clase social. Este concepto no puede denotar el mismo referente empírico cuando lo usa un hombre político que cuando lo usa un científico social. Para el primero, el criterio de validez de sus enunciados es la eficacia; para el segundo, el criterio de validez de sus enunciados es la veracidad. Para el primero, cuyos enunciados se dirigen a individuos y grupos de individuos, clase social denota un agregado de individuos; ésto es, denota un objeto. Para el segundo, cuyos enunciados no intentan persuadir políticamente a nadie, clase social denota una relación. El segundo cambia de discurso cuando adopta los criterios del primero ( $y$ no pongo el ejemplo converso, porque raramente los políticos se equivocan en cuanto a la identidad de sus públicos). A partir de esta distinción simple de los conceptos según que denoten objetos o relaciones ( $G$. Frege) podríamos analizar y reelaborar numerosos textos en los que clase social es usado alternativamente sin discriminación.

Usemos ahora un ejemplo procedente de las ciencias positivas. El concepto de equilibrio se encuentra en numerosas disciplinas; en cierta medida es uno de los conceptos «universales y simples». Hay que tomar distancia respecto de las proposiciones en las que este concepto es usado en abstracto. El equilibrio de una población de virus in vitro no es el mismo equilibrio que en un medio natural (en un organismo que los virus invadieron). Equilibrio como categoría universal no denota lo mismo que equilibrio como categoría analítica. El equilibrio de la población de virus está definido en relación a la magnitud de la población, a su organización, a su diferenciación, al espacio.

Algo similar podría decirse, en nuestro dominio social, con la categoría de dependencia. Esta carece de valor analítico si se la toma en abstracto. No es la misma dependencia la que define a un sistema económico cuyos recursos proceden de la minería o del monocultivo exportable, que la dependencia de un sistema económico cuyos recursos vienen principalmente de actividades financieras o fiduciarias por cuenta de terceros, o que, en fin, la dependencia de un sistema económico cuyos recursos son ya princi- 
Sistemas analíticos y sistemas empíricos...

palmente industriales pero que no ha alcanzado los niveles de acumulación tecnológica que son la propiedad de otro sistema más desarrollado y del cual se es dependiente.

\section{PODER Y DISTRIBUCIÓN DE PODER}

1. Volvamos a nuestros modelos de sistema político recogiendo algunas conclusiones de la interpolación metódica precedente.

La razón del carácter exhortativo de alguna frase en el texto precedente, es clara en una situación histórica de crisis como la nuestra. Hay muchas cosas que se derumban; el científico social aspira a que la crítica depure y deje intactas algunas piedras con las que construir un día un nuevo edificio.

En esta situación de crisis, llena de ambigüedades (lo único que sabemos con certeza es que, gracias al cielo, o a quien sea, es todo un sistema social el que se va al infierno), nos encontramos con hechos como el siguiente: Cualquier modelo retiene una parte de veracidad y al mismo tiempo produce una insatisfacción (tanto teórica como empírica); puede ser evaluado como una construcción que es aún pertinente, dentro de ciertas premisas, y una construcción que es ya inadecuada para aprehender los procesos del presente. En particular cuando las premisas son valores, o se basan en la reproducción cultural, la caducidad de los modelos y las teorías se hace espectacular.

Esto no significa que sean caducos la totalidad de los elementos de un modelo. La desaparición de los fundamentos económicos o culturales que hacían posible el sistema político dado, puede hacer olvidar de momento hasta qué punto las soluciones que encontró otra época u otra sociedad, implicaban ciertos principos cuya satisfacción es una necesidad permanente de todo grupo social. El respeto a la identidad dentro de la desigualdad, la conciliación de la libertad y la seguridad, la necesidad de hacer compatibles el enraizamiento y el cambio, la obediencia ante la autoridad y alguna forma de control general sobre la autoridad, son ejemplos de esos problemas fundamentales que se reencuentran planteados después de los períodos de crisis o los de absolutismo en nombre de algún principio unilateral y totalitario. Así, el hecho de que el modelo político liberal sea caduco, no quiere decir que no haya que recoger, para reinsertarlos 
Sistemas analíticos y sistemas empíricos...

en otro tipo de sistema político, algunos elementos necesarios: un cierto pluralismo, la garantía de las libertades humanas, el principio según el cual sólo el poder puede controlar al poder.

Los modelos se hacen caducos en otro sentido; exigen que las proposiciones analíticas enunciadas a partir de sus principios teóricos, tengan todavía una capacidad explicativa de los hechos. Generalmente (ésto es, salvo los casos particulares de las revoluciones) las formas se guardan durante un tiempo aunque ya no correspondan a un contenido, estén vaciadas o podridas. El hecho de que un modelo esté caduco no implica que haya que renunciar a examinarlo: hay que ver por qué lados se va derrumbando o vaciando de sentido.

2. Veamos algunos aspectos de interés en relación a la primera y la segunda concepciones de sistema político.

Las garantías y requisitos que deben ser respetados en el proceso de elaboración de decisiones políticas, responden a una concepción de la función del Derecho como integrador social. Habiendo sido elaboradas las normas jurídicas por intelectuales al servicio de las clases dominantes, sería ingenuo esperar que el contenido substantivo de ellas vaya contra los intereses de esas clases o los principios generales del orden social que controlan, por herencia o por apropiación. Sin embargo, en la medida en que no hay una sola clase dominante, y en que las clases política y económicamente dominantes no son las mismas, en la medida en que las dimensiones de clase se diferencian por otros cortes como el agrario / industrial, o el industrial / financiero, la multiplicidad de clases y de intereses exige la existencia de unas instancias de neutralización y de resolución de los conflictos, en las cuales son los requisitos técnicos del proceso de decisiones, y no la substantividad de las decisiones mismas, las garantías que convienen a los actores. Estos requisitos técnicos y estas garantías se hallan en principio accesibles a los miembros de las clases dominadas o subordinadas, y en este sentido se ha acumulado desde el primer tercio del s. Xrx toda una literatura sobre el Derecho como garante de la libertad del débil frente a los recursos o la coacción del fuerte. La función de los requisitos técnicos que es visible en el dominio jurídico, se ha especificado asimismo en el sistema político, en la limitación de la arbitrariedad y la discrecionalidad del Ejecutivo y de la Administración, tanto por normas que reglan la actividad de sus miembros, como por la necesidad de la aprobación formal de sus decisiones por otros actores políticos, dotados o no de iniciativa propia, o en fin por la posibilidad de recurso ante otras instituciones que las políticas. Una aprobación obtenida bajo amenaza es así considerada ilegal. Las normas explícitas y las reglas de juego 
Sistemas analíticos y sistemas empíricos...

implícitas en el funcionamiento del sistema, suponen la libertad de los actores. Esta concepción ha sido generalizada y valorizada tan precisamente, que los profesionales de la función representativa pueden no seguir un mandato tácito de sus electores y (desde Burke se dice deben) actuar en el Parlamento «según su propia conciencia»; es decir: su libertad no se supone sólo frente al poder ejecutivo o frente a otro actor situado encima del Ejecutivo, sino asimismo frente al cuerpo de los ciudadanos, teóricamente sus mandantes (y depositarios de la soberanía). La congruencia de esta concepción respecto a una sociedad en que las bases pluriclasistas, patrimoniales y privadas, permiten la independencia económica de los representantes, es obvia, y basta recordar las minuciosas descripciones de los políticos pro-tempore hechas por Max Weber en Politik als Beruf, para ver la adecuación entre el pluralismo social basado en una distribución de la riqueza patrimonial, el ejercicio temporal de una función política, la función de las reglas de juego entre los actores, y la legitimación social del sistema.

¿Qué ocurre cuando la sociedad civil va perdiendo su caracter pluralista, o mejor dicho, las condiciones económicas de independencia patrimonial de los profesionales de la política, para mantener solamente el pluralismo derivado de las divisiones social y técnica del trabajo, cada vez más especificadas y atomizadas? Dicho más crudamente: ¿qué ocurre cuando la inmensa mayoría de los individuos con intereses permanentes o temporales en la actividad política, son unos funcionarios, dependientes de organizaciones privadas o públicas?

Primeramente, Ia carrera política tiende cada día más a empezar y pasar por los contactos y la experiencia adquiridos en cuanto funcionario. Se sale de determinadas escuelas de élite o universidades como alto funcionario. Se participa en reuniones donde se toman decisiones sin compartir la responsabilidad por ellas. La autoridad conferida por la función representativa, deviene una especie de apoyo moral residual, una legitimación conveniente pero que ha dejado de ser la fuente de la autoridad. Dada la progresiva transformación de las prácticas electorales basadas en el sufragio universal, en sistemas plebiscitarios, importa más gozar de la confianza del dirigente plebiscitado que del Parlamento o de los supuestos depositarios de la soberanía - (dirigente que, dicho sea sin ironía, puede ser a su vez otro funcionario, convenientemente plebiscitado después de cooptación por sus pares.)

Dado que, por definición, la democracia dentro de la burocracia es un contrasentido, una buena parte de la actividad de los «funcionarios de todas clases» consiste en crearse las áreas discrecionales más aisladas posibles, ésto es, tratar de reunir las ventajas de la centralización técnica 
Sistemas analíticos y sistemas empiricos...

moderna con una división feudal del campo ejecutivo y administrativo. Las decisiones políticas se toman en gabinetes o reuniones donde no hay reglas de juego establecidas entre actores institucionalizados. ¿Con qué autoridad? Con la autoridad delegada por el dirigente plebiscitado, o por alguien de su gabinete.

Se ha hablado mucho de los grupos de presión actuantes sobre el Ejecutivo y sobre la Administración en general; no se habla tanto, y no es menos interesante observarlo, del hecho de que uno de los más eficaces grupos de presión actuantes sobre el Ejecutivo y el Parlamento, es decir, sobre unos funcionarios, lo constituyen otros funcionarios, ésto es, ramas o cuerpos de la propia Administración.

El sistema político produce cada vez menos reglas para normar su propia actividad en función de unos principios de equidad o de Derecho, y cada vez más reglamentos para delimitar actividades sectoriales en orden a principios organizativos y delegaciones de autoridad como en las organizaciones no políticas: delegaciones desde arriba, basadas en ciertos criterios de eficacia y no en principios de legalidad e integración política o social. A su vez, el sistema produce cada vez más decisiones sin pasar por los requisitos legales y técnicos en los que podría fundarse la legitimación social de su acción. Son decisiones que interesan a los miembros del propio sistema, no al cuerpo de ciudadanos; son decisiones propias de una concepción del sistema como red de sinecuras y oportunidades, ésto es, un «fondo a consumir». Las tensiones entre tecnócratas más o menos manifiestos y políticos profesionales más o menos puros, pueden revestirse de una gran retórica sobre el interés del Estado o de la nación; y dado que el sistema capitalista avanzado produce nuevas clases sociales, el sociólogo que confunde los funcionarios con las fuerzas productivas puede sentirse tentado a ver esas tensiones en el interior del sistema político como el reflejo de nuevas luchas de clases en la generalidad de la sociedad. Con ello se desplaza la atención del lugar social en que ocurren las verdaderas luchas de clases, y se reviste del ropaje de éstas a lo que son contiendas de influencia.

El proceso que estamos describiendo, y que podría ser simplificado en una frase como el de la destrucción del sistema fundado en los requisitos legales del decision-making y el paso a un sistema basado en la distribución de influencia, es un proceso en el que van envueltas muchas dimensiones, algunas de las cuales han recibido una atención analítica considerable, mientras otras han sido apenas tocadas. Entre las primeras está la literatura sobre la decadencia de los Parlamentos y el progresivo vaciamiento de la función representativa; sobre la aparición de nuevos centros de decisión; sobre los grupos de presión; sobre las esclerosis buro- 
Sistemas analíticos y sistemas empíricos...

crática u oligárquica en los partidos políticos; sobre la adopción de funciones parcialmente representativas y de reivindicaciones políticas generales por organizaciones diferentes de los partidos políticos, como los sindicatos. El sólo enunciado de estos temas muestra que se trata de partes de un proceso total, en virtud del cual hay áreas del viejo sistema político que dejan de funcionar, o cuyo funcionamiento se mantiene sólo pro-forma con matices de farsa, mientras el sistema se ensancha con la adición de nuevas áreas o con la adopción de funciones políticas por organizaciones que antes se hallaban en la frontera de él y que ahora están dentro (caso del desplazamiento de ciertas funciones representativas y reivindicativas, de los partidos dominados por aparatos burocráticos y alejados de los problemas sociales reales, a los sindicatos).

Es significativo observar que hay áreas de decisiones en las cuales el margen de libertad de los actores se ha reducido considerablemente, en tanto que en las nuevas áreas (paralelas a las nuevas incursiones del Estado o de autoridades no precisamente estatales, en campos hasta ahora no reglamentados política o legalmente de la actividad civil), los grados de libertad de los actores son mucho mayores, y son en estas áreas donde se libran las contiendas de influencia.

La reducción del margen de libertad en las funciones y áreas tradicionales de decisiones, es espectacular en el caso del Presupuesto y de la función de control del Parlamento.

No quisiera trivializar el argumento recurriendo a la anécdota histórica, pero será útil que observemos al menos dos ejemplos, que conciernen respectivamente la primera y segunda concepciones de sistema político.

Según los términos de la primera concepción, hay por lo menos un producto del sistema político en el cual éste revela todas sus virtualidades, producto que por lo tanto suele ser distinguido cualitativamente. Este es ese fruto de la relación de concordancia de voluntades entre actores políticos y al mismo tiempo de control de uno de ellos sobre la iniciativa o la discrecionalidad del otro, que se 1 lama en Gran Bretaña the Finance Act, en Francia la Loi de finances, o en España la Ley de Presupuestos. El presupuesto (con todo el «ambiente» que aún es visible, por ejemplo, en torno al Canciller del Exchequer el día de la presentación al Parlamento) constituye ciertamente un caso privilegiado entre los productos del sistema político:

(a) por sus antecedentes, que nos remiten a la función de fiscalización que los representantes han ejercido tradicionalmente sobre los gobernantes;

(b) por su capacidad de mantener o alterar ciertos principios de equidad social, mediante el manejo de los baremos de los impuestos (e incluso, 
si ésto no se hace en otras leyes específicas, por la creación de nuevos impuestos o el desuso o abolición de algunos de los antiguos);

(c) por sus efectos eventuales sobre la actividad del sistema económico del país.

Será ocioso que llame la atención de los lectores, sin ironía, sobre la considerable literatura que los expertos han elaborado, desde mediados del siglo XIX, sobre la naturaleza de esa ley que es a la vez anual y poseedora de efectos legales trascendentes (a pesar de ser una ley anual, un impuesto creado por ella sobrevive a la ley).

Si se considera que un sistema político es un sistema productor de decisiones, implícitamente se otorga a los actores una cierta capacidad discrecional. Observemos cuál es la realidad. Entre el $85 \%$ y el $90 \%$ del monto global de un presupuesto, es intocable por el ministro de Hacienda, el cual está obligado a reproducir los gastos del presupuesto anterior (esta declaración defensiva según la cual su margen de libertad presupuestaria es inferior al $15 \%$, procede del ministro francés de Hacienda, M. Giscard d'Estaing). Si las contiendas de influencia en el interior del gabinete del ministro, han girado en torno a poco más del diez por ciento del monto global del Presupuesto, ¿qué se deja a los diputados para modificar, ampliar o recortar? Un diez por ciento de ese diez por ciento. Probablemente los diputados y senadores no tendrán ni el tiempo de leer la montaña de documentos elaborados por los técnicos; y a veces el desprecio de los técnicos por la incomprensión que algunos diputados muestran respecto del lenguaje técnico, se hallará justificado. Digamos en suma que la máxima decisión legal del sistema político se nos aparece así, más que como la expresión de una voluntad, como la consecuencia de un sistema de inercia.

Se objetará que los juegos de palabras no son inocentes; que si eso ocurre en el presupuesto, es porque hoy los gobiernos tienen la capacidad de hacer grandes gastos e inversiones que no someten a la fiscalización parlamentaria, y que se hacen en términos de otras autorizaciones legales o de ninguna (como ciertos gastos de Defensa y seguridad). La objeción es correcta en cuanto a la observación de la realidad. Simplemente, si se efectúan grandes gastos e inversiones sin autorización legal deja de existir ipso facto el recurso de ilegalidad contra esas decisiones. La reserva de las prioridades políticas implica que no hay imputación de voluntad legal a una persona jurídica. Siempre hubo, ciertamente, una discontinuidad entre el derecho privado y el público, pero no hasta el punto de que la prioridad de los intereses políticos hiciera desaparecer el sujeto jurídico de la voluntad.

Con ello queda herido uno de los principios fundamentales de la se- 
Sistemas analíticos y sistemas empíricos...

gunda concepción de sistema político, el vínculo entre autoridad y responsabilidad.

No es ajeno a este proceso el hecho, observable en los años más recientes, de que en los países capitalistas avanzados los gobiernos traten de desplazar cada vez más la fuente de legitimación social de su acción, del área interna al área de la política exterior. Incapaces de acometer las reformas sociales que se proclaman tan sistemáticamente como se aplazan, se manipulan las decisiones de política exterior en dos formas aparentemente antagónicas pero que son las dos caras de una misma medalla: por una parte, como decisiones extremadamente técnicas e incomprensibles para el ciudadano común, e incluso excluidas de su conocimiento en cuanto relevantes de los problemas del equilibrio nuclear mundial; por otro lado, como el área privilegiada de la acción gubernamental, en la cual se realizan o se unifican todos los grandes principios nacionales: la grandeza, la seguridad, el rango de Potencia internacional, la parte de poder y de control en el sistema monetario internacional, etc. Tanto en un caso como en el otro, la responsabilidad es difusa y se remite a ese actor abtsracto que se llama «la historia». $Y$ en ambos casos hay una especie de retorno a una situación que era la característica del sistema europeo de Potencias bajo el Ancien Régime: los asuntos más importantes de gobierno se hallan, por demasiado técnicos, excluidos del conocimiento y de la sanción de los ciudadanos.

3. Durante largo tiempo se han opuesto en la teoría social y en la teoría política dos campos, el constituido por las teorías de la integración o el consensus, y el constituido por las teorías del conflicto. Parece llegado el momento de reemplazar los términos de esta antinomia por otros más fieles a la situación presente. La pregunta de fondo que se plantean ambas teorías es la misma, es la vieja cuestión de Hobbes y de Spinoza, ¿cómo conseguir que se mantenga integrado un sistema social, y más específicamente un sistema político? La respuesta según la cual el sistema se mantiene integrado gracias a la reproducción cultural, resulta hoy insatisfactoria. Se sigue llamando consensus a lo que es pasividad de los ciudadanos. Se llama consensus a la obediencia. La expectativa de obediencia es una de las propiedades de la relación de autoridad (Dahrendorf), y en estos términos un sistema político podría ser redefinido, estrictamente, como un sistema de relaciones de autoridad que se satisfacen en la obediencia mínimamente necesaria para que el sistema se mantenga.

Ahora bien, esta concepción excluye todas las demás y cierra el 
campo analítico de una manera tan estrecha que quedan fuera de él una considerable variedad de fenómenos políticos, que son del máximo interés. La contrapartida de la obediencia no es la misma que la que existe en las relaciones interindividuales de autoridad en el seno de una organización jerárquica. La contrapartida política de la obediencia es el paternalismo instrumental de los actores políticos. Estos mandan y obedecen, no en razón a valores ni en razón al exquisito cuidado legal con que fueron elaboradas las decisiones, sino en razón de que, para ser obedecidos, unos actores otorgan concesiones en la distribución de ciertos bienes socialmente escasos, todo y manteniendo el control sobre ellos. El concepto que hace pareja con el de obediencia es el de paternalismo. En esta dimensión, no sólo no se descubre, pues, nada nuevo, sino que la situación presente sería un retorno a una de las más viejas y rudimentarias formas de la relación de autoridad. Esta funciona, no por interiorización de valores ni por participación en el proceso de decisiones, sino por un proceso de learning: se adiestra al animal que recibe alimento cuando aprende a orientarse en el laberinto.

Tal es una parte de la verdad: el retorno a una relación rudimentaria y primitiva en el contexto social moderno, artificialmente complicado.

Veamos ahora los otros hechos que quedan fuera de esa dimensión y que son del mayor interés.

Mi primer postulado, formulado negativamente, es que la observación de un sistema político no puede limitarse a la observación de conductas; pero que en modo alguno puede procederse a su substitución por abstracciones, como si las conductas fuesen la expresión material de principios inmanentes (que en definitiva estarían, en toda su pureza heurística, sólo en la cabeza del sociólogo). Dicho positivamente, (a) hay que partir de las conductas para trascenderlas analíticamente ( $y$ sólo en este sentido la razón puede oponerse a la experiencia); (b) en los sistemas hay otros muchos elementos además de las conductas, los cuales exigen ser observados y analizados; de algunos de ellos hablaré luego.

Un sistema definido sólo en términos de autoridad y de la expectativa de obediencia (Dahrendorf: el actor A espera fundadamente ser obedecido por el actor B), no hace sino reformular en una relación social concreta (llamada política) el modelo de las expectativas recíprocas y complementarias de la acción social de Weber. ¿Es éste el modelo que conviene a las relaciones que observamos cada día entre actores políticos?

Tanto si se trata de relaciones entre gobiernos (las relaciones llamadas internacionales), como si se trata de relaciones entre un gobierno y una organización patronal o empresarial, o entre la organización patronal y una organización sindical, o entre un gobierno y unos sindicatos obreros, más 
Sistemas analíticos y sistemas empíricos...

fielmente se diría que las relaciones entre actores se caracterizan no por la reciprocidad de las expectativas sino por la incertidumbre de cada actor jobre la acción que, a su encuentro, adoptará el otro. El gobierno A se Breguntará constantemente cual es la acción previsible del gobierno B "respecto a él: acción de coerción, de persuasión, de negociación, etc. Las relaciones llamadas internacionales no se definen por la reciprocidad de expectativas más que en dos casos particulares (el de la dominación global de un gobierno sobre otro, y el de la complementariedad perfecta de intereses), los cuales, siendo particulares, no pueden ser usados para definir una relación general.

Si los actores son, por ejemplo, una organización sindical y un gobierno, ¿no estamos en presencia de una situación análoga? ¿Cuántas veces no hemos visto que cuando un sindicato obrero se dirigía a un gobierno esperando obtener ciertas medidas legales reformistas, encontraba como respuesta la represión violenta, no en nombre del orden legal sino del orden público?

Si los actores son una organización patronal y un sindicato, ¿cuántas veces no hemos visto que cuando los empresarios esperaban el consensus de sus obreros sobre unas decisiones, el sindicato respondía por una huelga llevada con determinación hasta el nivel de su propia derrota?

Estas proposiciones son válidas también cuando se constituyen nuevos actores. En todos los países occidentales industrializados observamos hoy con frecuencia el caso del sindicato desbordado por las secciones sindicales de fábrica, o por grupos o comités creados espontáneamente por los obreros en desafío a las consignas y jerarquías sindicales; ésto es, la creación de actores políticos transitorios a partir de ciertas dimensiones latentes.

Digamos que las relaciones que se observan en un sistema político no pueden reducirse al caso de la reciprocidad de expectativas que corresponde a la relación «autoridad - obediencia». Este modelo conviene a un territorio analítico particular, el de las organizaciones jerárquicas. En el caso de las instituciones legales ( $\mathrm{y}$ concretamente de la relación entre el Estado y los ciudadanos) habrá obediencia del súbdito y expectativa de obediencia desde la posición del Estado, pero no reciprocidad de expectativas. En el caso de actores políticos que, aunque poseedores de poderes desiguales, son capaces de negociar o enfrentarse, de aliarse o de destruirse, lo que observamos es una situación de impredictibilidad de la acción. En este último caso podrá llegar a existir una reciprocidad de expectativas, como un resultado, no como premisa.

Ahora bien, la reciprocidad de expectativas funciona como una propiedad social en cuanto está interiorizada por los actores. Tiene, pues, una dimensión subjetiva. La impredictibilidad de la acción es completamente 
subjetiva. Un sistema de relaciones de poder (y en ese sentido, sistema: político) puede hallarse fuertemente determinado sin que los actores lo. perciban como tal (puede percibirlo así un observador externo); los actores pueden incluso percibir una determinación que no es tal o que no. corresponde a la real. Impredictibilidad (subjetiva) de la acción no es una categoría contradictoria con la de determinación. George F. Kennan gustaba hablar de la impredictibilidad de la historia; sin embargo, en cuanto. formulador de algunos principios fundamentales de la política exterior de los Estados Unidos desde 1946, contribuyó grandemente y personalmente a la determinación del sistema mundial de poderes. El ataque de Hitler a la Unión Soviética en junio de 1941 suele ser citado como ejemplo de la impredictibilidad y a veces de la gratuidad de ciertas decisiones (gratuidad siendo sinónimo de no necesario). Nada más falso como ejemplo. Basta leer cuidadosamente los Prolegómenos a la Guerra en el Este de G. Gafenco para advertir que, dadas las condiciones creadas por el reparto Ribbentrop-Molotov de septiembre de 1939, el III Reich tenía que acabar atacando a la U.R.S.S., independientemente de la existencia de un individuo: como Hitler.

En este sentido, un texto reciente de cierta importancia por las cuestiones e interrogantes que se plantea (L'explication politique, de Alfred Grosser, París 1972), es por otro lado decepcionante en cuanto desemboca. en unas conclusiones tan generales de indeterminación que harían imposible otro conocimiento que el taxonómico o clasificatorio; no tendría. fundamento hablar ni de sistemas, y mucho menos de sistemas determinados.

4. Hablemos, pues, finalmente del poder; en vez de hablar de valores, de legalidad, de autoridad, de influencia, de control, de dominación, o de otros supuestos equivalentes suyos. No podemos compartir la tesis (Bergeron et al.) según la cual el concepto de poder es ambigüo, inútil y anticientífico, y debe ser desterrado para siempre del análisis de los sistemas. políticos. No vemos cómo es posible afirmar que un sistema político esté determinado por otra cosa que por una relación de poder.

La arremetida contra el concepto de poder es, o bien (a) anacrónica, en cuanto dispara contra la categoría metafísica tal como la usaban en la segunda mitad del siglo xIx Droysen y Treitschke, y como se siguió usando en el Reich hasta 1945; o bien (b) es una arremetida de buena fe ideológica (el poder es ciertamente inútil si los sistemas se autorregulan por sus funciones); o bien, finalmente $(c)$, es una arremetida de mala fe cientiffica: quienes postulan que deje de hablarse del poder, son preci- 
Sistemas analíticos y sistemas empiricos...

samente los que tienen y ejercen poder, o los que elaboran teorías que sirven a los poderosos.

Es necesario cualificar analíticamente la categoría de poder, sin hacerla desaparecer bajo otras categorías que denotan otro tipo de relaciones (particularmente, las de autoridad e influencia).

Aquí el investigador social debe declarar honestamente que la solución que dé al problema no es políticamente neutra (postulado de Myrdal). El hace una elección teórica porque ésta corresponde a su concepción de las relaciones entre actores políticos concretos.

Vemos que al poder se lo concibe como una esencia misteriosa que está por todas partes: en la familia y en la escuela, en la empresa y en el Tribunal supremo. No es inocente la paradoja de que en esta percepción coincidan sociólogos liberales y los paleomarxistas ingenuos. Los sociólogos liberales establecen clasificaciones de poder que sólo tocan algunos de los lados de la cuestión de la determinación. Tomemos por ejemplo la clasificación de poder más reciente y general (Etzioni): poder normativo, poder instrumental, poder coercitivo. Esta tipología evidentemente no es neutra. La más simple reflexión sobre cada uno de los tres tipos nos dice que el poder normativo (de origen metapolítico) es relativamente difuso en un sistema social, y en cuanto tal se halla implicado en relaciones de naturaleza asaz dispar (en la familia, en la escuela, en las iglesias, quizá en las unidades de producción escasamente diferenciadas y jerarquizadas). El poder instrumental está localizado en las relaciones que tienen lugar en organizaciones económicas; y, en fin, el poder coercitivo lo está en el Estado.

En otros términos: la tipología admite que la distribución de poder es no aleatoria (es not random) y eso es todo. Nada dice sobre las condiciones y determinantes por los cuales una distribución de poder es no aleatoria. Cuando este problema se plantea, entonces se nos responde simplemente que para que un sistema político funcione y realice sus fines, es necesario que existan unidades de control internas al sistema (o en «jargon», que la distribución direccional debe oponerse permanentemente a la distribución entrópica).

Así la cuestión de la distribución del poder es relativamente ignorada, en cuanto si bien se admite que la distribución es no aleatoria, inmediatamente se pasa a aceptarla como un dato, un hecho natural.

Cuando la cuestión de la distribución del poder ha sido planteada, lo ha sido en un bajo nivel de abstracción. Se ha visto al poder sólo en una dimensión, localizado en personas o grupos (Wright Mills). El poder es entonces un «bien» escaso por su propia naturaleza, las cantidades que unos ganan otros las pierden, y el sistema es de suma cero. Es la con- 
cepción adecuada en çirienes tienen débiles, o ninguna, capacidad de creación de poder o de transformación de poder latente en poder manifiesto. Frente a esta concepción los sociólogos liberales pudieron ser liberalmente magnánimos y distributivos: Parsons y otros importantes seguidores del estructural-funcionalismo americano contestaron que el poder es un atributo generalizado de toda la comunidad, no sólo de personas. Con lo cual se afirmaba una verdad (que toda comunidad posee unos sistemas de transformación de poder latente en poder manifiesto) al mismo tiempo que al afirmarse la propiedad difusâ de ese poder se olvidaba la cuestión de la distribución del otro poder, el poder de controlar el sistema. Y quien dice control, dice control de alguien y para algo.

El sistema político nos presenta dimensiones diferentes según reposemos la atención sobre el poder que encauza demandas y las reelabora hacia la consecución de fines de interés general; en el poder de direccionalidad del movimiento (la elección de ciertos fines y la exclusión de otros); o finalmente, en el poder para mantener o alterar unas distribuciones de poder.

Dado que en las ciencias sociales hay tantas «soluciones» meramente verbales, podría decirse que esta última propiedad es la dominación.

Una vez más las palabras no son inocentes. El lector se habrá percatado de la conclusión implícita en nuestro argumento: han hecho crisis los modelos basados en los valores y en la legalidad, quedan frente a frente dos concepciones relativamente válidas: la que se basa en la eficacia (la tercera concepción de sistema político) y la que se basa en la dominación (la cuarta).

Digo relativamente, porque ciertos fenómenos como la acumulación episódica de enormes poderes en el seno de organizaciones o grupos que, originados en las relaciones sociales cotidianas e incluso institucionalizados, concluyen por «distanciarse de la sociedad» y por oprimirla, son fenómenos del mayor interés y no previstos en el sistema. Aún no han recibido satisfactoria explicación cosas como el nazismo y el stalinismo, que se desarrollaron en el brevísimo espacio de unos años a partir de situaciones en las que el sistema social no permitía prever tales acumulaciones de poder. Esta observación, guardadas sean las distancias, podría aplicarse asimismo a situaciones más recientes, incluidas las llamadas democracias.

La elegancia cibernética de la tercera concepción del sistema político me hace sugerir que, si bien es cierto que con la operación del principio de eficacia nos encontramos de nuevo todos reunidos (¿para qué excluir a nadie? y sobre todo, ¿para qué un principio de exclusión fundado en valores metapolíticos?), en cambio sería pertinente decir que el modelo contiene una idealización. Me pregunto si el postulado de James C. Miller 
Sistemas analíticos y sistemas empiricos...

que pide un alto grado de isomorfismo entre los dos sistemas (el conceptual y el empírico) como condición del avance de la ciencia (sic) es un postulado adecuado para la sociología política. La elegancia formal así conseguida, ¿no obliga a una formalización ideal del sistema empírico, antes incluso de traducirlo al lenguaje y a los términos del sistema conceptual?

(Concluirá) 